\title{
İskenderiye Üçgülü (Trifolium alexandrinum L.) Islah Çalışmaları*
}

\author{
Celal YÜCEL ${ }^{1} \quad$ Mustafa AVCI $^{2} \quad$ İlker İNAL ${ }^{1} \quad$ Murat Reis AKKAYA $^{3}$ \\ ${ }^{1}$ Doğu Akdeniz Tarımsal Araştırma Enstitüsü Müdürlüğü, Adana \\ ${ }^{2}$ Ömer Halisdemir Üniversitesi, Tarım Bilimleri ve Teknolojileri Fakültesi, Niğde \\ ${ }^{3}$ Adana Bilim ve Teknoloji Üniversitesi, Mühendislik ve Doğa Bilimler Fakültesi, Adana \\ $\bowtie$ : celalyucel1@gmail.com
}

Geliş (Received): 02.11.2017

Kabul (Accepted): 15.12.2017

\begin{abstract}
ÖZET: Araştırma, Çukurova bölgesine uygun kışlı ara ürün yetiştirme döneminde tarımı yapılabilecek, ot verimi ve kalitesi yüksek yeni İskenderiye üçgülü (Trifolium alexandrinum L.) çeşitlerinin geliştirilmesi amaciyla yürütülmüștür. Araştırma, popülasyon karakterindeki materyalde, kendine döllenen bitkilerde uygulanan tek bitki seleksiyonu yöntemiyle, Adana Doğu Akdeniz Tarımsal Araştırma Enstitüsü Araştırma Alanında, 2010-2015 yılları arasında kışlık dönemde yürütülmüştür. Araştırmaya, Kasım 2010'de 70 x70 cm aralıklarla 2000 tek bitki elde edilecek şekilde kaynak popülasyonu ile başlanmışıtır. 2011 yılında 200 tek bitki, 2012 yılında 70 tek bitki sırası, 2013 yılında ise 22 genotip seçilmiştir. 2013-14 ve 2014-15 yıllarında standart çeşitlerinde yer aldığ 125 genotiple çeşit verim denemelerine devam edilmiştir. Araştırmada çeşit verim denemeleri, tesadüf blokları deneme deseninde 4 tekrarlamalı olarak yürütülmüştür. Çeşit verim denemeleri sonucunda, genotiplerin çiçeklenme gün sayısı, kuru madde verimi, sindirilebilir kuru madde verimi, ham protein oranı ve nispi yem değeri sırasıyla 120.0-132.8 gün, 894-1222 kg da-1, 4449.7-611.5 kg da-1, \% 14.02-17.21, ve 80.5-102.2 arasında değişim göstermiştir. İki yıllık çeşit verim denemeleri sonucu 3,4,13,10,17,14 ve 7 no'lu genotiplerin verim ve bazı kalite değerleri bakımından diğer genotiplerden üstün oldukları saptanmıştır. Söz konusu genotipler, ileride yapılacak islah çalışmalarında değerlendirilecektir.

Anahtar Kelimeler: İskenderiye üçgülü, sslah, genotip, verim, kalite
\end{abstract}

\section{Researches of Berseem Clover (Trifolium alexandrinum L.) Breeding}

ABSTRACT: The research was carried out with the aim of developing new Berseem clover (Trifolium alexandrinum L.) varieties with high yield and quality, which can fit well to the winter-mid cropping season in Çukurova region. At the initiation, we started off with a population of berseem clover was available by the Institute and also single plants selection method was implemented as used in self-pollinated crops. The experiment was arranged in a randomized complete block design with three replications at the Experimental Field of Eastern Mediterranean Agricultural Research Institute in Dogankent (Adana/Turkey) as winter crops in winter period of the 2010-2015. As a source population, the breeding-nursery, consisting of 2000 spaced plants were established $(70 \times 70 \mathrm{~cm})$ in first year, 200 single plants were selected in first year, 70 plant rows were selected second year and, 22 genotypes were selected thirty year. Yield-trail experiment was carried out in 2013/14 and 2014/15 years with 25 genotypes. According to the means of the combined two years; days to flowering, dry matter yield, digestibility dry matter yield, crude protein ratio and relative feed value were changed between, 120.0-132.8 days, 894.0-1222.0 kg da-1, 449.7-611.5 kg da-1, 14.02-17.21\% and 80.5-102.2, respectively. According to the result, it was concluded that some genotypes in terms of dry matter yield and other forage quality characteristics. Bersem clover cv. 3, 4,13, 10, 17, 14 and 7 were superior than other genotypes in Çukurova conditions. These genotypes are ready to use in future breeding programmes.

Keywords: Berseem clover (Trifolium alexandrinum L.), breeding, genotype, yield, quality

\section{GíRis}

Tüm Akdeniz ülkelerinde çok eski yıllardan beri yetiştirilmekte olan İskenderiye üçgülü (Trifolium alexandrinum L.) tek yıllık, yarı kurak koşullara iyi uyum sağlayan, serin mevsim baklagil yem bitkisidir. Tek biçimden bir çok biçime kadar değişen çeşitlere sahip olmasına karşın, en yüksek ot veriminin daha çok 1. ve 2. biçimlerden alınmakla birlikte, yem değeri yonca kadar önemli olan bir baklagil yem bitkisidir (Tansı ve ark., 1989; Iannucci ve ark., 1996; Çelen ve ark., 1991; Ranjbar, 2008). İskenderiye üçgülü kuvvetli bir köke sahip, yan kökleri ince olup, bol miktarda nodozite içermektedir. Yıllık yağışı $400 \mathrm{~mm}$ den fazla olan yerlerde iyi gelişen, soğuğa hassas, sıcak iklimleri seven, nötr ve hafif alkali topraklarda iyi gelişen, hafif tuzluluğa dayanıklı, ilk biçimin ot üretimine, diğer biçimlerin ise otlatma amacı ile de kullanıldığ bildirilmektedir (Gençkan, 1983; Açıkgöz, 2001). İskenderiye üçgülünün yararları, tohumu benzerlerinden ucuz oluşu, çok hızlı gelişerek çok biçim vermesi, ana ve ara ürün olarak kullanılabilmesi, karışımlara girdiğinde verimi yükseltmesi, yeşil yem olarak sığır ve 
domuzlarca istekle yenmesi, birim alanda fazla miktarda kaliteli yem sağlaması, bazı tiplerinin otlatmaya uygun oluşu şeklinde ifade edilmektedir (Gençkan, 1983). İskenderiye üçgülü yalın veya buğdaygillerle karışım şeklinde yetiştirilerek kaliteli kaba yem elde edilmektedir. Araştırma, Çukurova bölgesine uygun kışlık ara ürün yetiştirme döneminde tarımı yapılabilecek, ot verimi ve kalitesi yüksek yeni İskenderiye üçgülü (Trifolium alexandrinum L.) çeşitlerinin geliştirilmesi amacıyla yürütülmüştür.

\section{MATERYAL ve METOT}

Araştırmada kaynak popülasyonu elde edilmesinde, uzun yıllardan beri (20-25 yıl) tarafimızdan tarımı yapılan İskenderiye üçgülü popülasyonu materyal olarak kullanılmıștır.

Denemelerin kurulduğu alandaki toprak örneğinde yapılan analizler sonucunda; toplam tuz \%0.026, $\mathrm{pH}$ değeri 7.72, ortalama kireç içeriği \% 20, organik madde $\%$ 2, kum \% 27.8, kil \% 31.2, silt ise \% 41 olarak saptanmıştır (Ç.Ü. Ziraat Fakültesi Toprak Böl. Lab. Sonuçları). Araştırmanın yürütüldüğü 5 yıl süresince sadece, çeşit verim denemelerinin yürütüldüğü birinci yılda (2013 Kasım-2014 Mayıs) yeterli ve düzenli bir yağış dağılımı olmamıştır. Vejetasyon süresindeki toplam yağış miktarının 2013-2014 döneminde 189.1 $\mathrm{mm}$, 2014-2015 döneminde ise $656 \mathrm{~mm}$ olarak saptanmıştır.

Proje, kendine döllenen bitkilerde tek bitki seleksiyonu yöntemiyle sürdürülmüştür (Anonymous, 1987). Araştırma, Doğu Akdeniz Tarımsal Araştırma Enstitüsü Deneme alanında 2010-2015 yılları arasında Kasım-Haziran kışlık ara ürün döneminde sürdürülmüştür.

2010-2011 yılı çalışmaları: Araştırmada 2010 Kasım ayında 70 × $70 \mathrm{~cm}$ aralıklarla 2000 tek bitki elde edilecek şekilde kaynak popülasyonu oluşturuldu. 200 tek bitki belirlenmiştir (Mayıs-2011). Belirlenen tek bitkiler ayrı ayrı hasat edilerek tohumları ayrı ayrı olacak şekilde temizlenerek muhafaza edilmiştir.

2011-2012 yılı çalışmaları: Mayıs 2011 döneminde seçilen 200 tek bitki, Kasım 2011 döneminde tekrar 70 x $50 \mathrm{~cm}$ aralıklarla 2000 tek bitki parseli oluşturuldu. Her genotip $5 \mathrm{~m}$ uzunluğunda $70 \mathrm{~cm}$ sira arası ve $50 \mathrm{~cm}$ sıra üzeri olmak üzere her genotipten 10'ar bitki olacak şekilde elle ocak usulü ekilmiştir. Mayıs-Haziran 2012 döneminde 70 bitki sırası belirlenmiştir.

2012-2013 yılı çalışmaları: Mayıs 2012 döneminde seçilen 70 tek bitki sıraları, Kasım 2012 döneminde tekrar $70 \mathrm{~cm}$ sira arası ve $5 \mathrm{~m}$ uzunluğunda ekimleri yapılmıştır. Bitkilerin \% 50-100 çiçeklenme gösterdiği dönemde $5 \mathrm{~m}$ uzunluğundaki sıranın parsel kenarlarında $0.5 \mathrm{~m}$ kenar tesiri olarak atıldıktan sonra geriye kalan 2 $\mathrm{m}$ ot verimi ve ot kalite değerlerinin saptanması amaciyla diğer $2 \mathrm{~m}$ tohum amaciyla hasat edilmiş ve parsel verimleri saptanmıştır. Ot verimi, kalitesi ve tohum verimleri ile birlikte incelenen tüm özellikler göz önünde bulundurularak, 70 genotip 22 genotibe indirilmiştir.
2013-2014 ve 2014-2015 yılı çalışmaları: Seçilen 22 genotibe birlikte Alex ve Derya standart çeşitleri ile birlikte toplam 25 genotiple 2013 Kasım ayında çeşit verim denemeleri kurulmuştur. Çeşit verim denemeleri tesadüf blokları deneme deseninde 4 tekrarlamalı olarak kurulmuştur. Hasatlar \%50-100 çiçeklenme dönemine denk gelen zamanda yapılmıştır. Ayrıca, kaliteyi doğrudan etkileyen yaprak/sap oranları da belirlenmiştir. Parsel biçimleri sırasında alınan $500 \mathrm{~g}$ yaş ot örneği, yaklaşık 2 gün süre ile $65^{\circ} \mathrm{C}$ sıcaklıkta ağırlıkları sabitleşinceye kadar kurutulup, tartılarak kuru ot oranları (\%) belirlenmiştir. Kuru ot oranları ile yaş ot verimlerinin çarpımında kuru ot verimleri saptanmıştır. Tartılan 500 g kuru ot örneği, yaprak ve sap kısımları ayrılmış, ayrı ayrı tartılarak \% oranları saptanmıştır. Daha sonra yaprak ve sap örnekleri ayrı ayrı ögütülerek kalite analizleri yapılmıştır. Kalite analizleri sonucu yaprak ve sap oranları da dikkate alınarak ortalama bitki kalite değerleri saptanmıştır. Ot kalite analizleri Enstitümüz bünyesinde yer alan kalite laboratuvarında NIRS (Near Infrared Reflectance Spectroscopy) analiz cihazıyla kıyaslamalı olarak (Shenk ve Westerhaus, 1994) The FOS XDS C0904FE-Hay and Fresh Forage kalibrasyonunda yapılmıştır. Sindirilebilir kuru madde (SKM) Jaranyama ve Garcia (2004): SKM (\%): (88.9(0.779 x \% ADF, Kuru madde alımı NDF: DMI (\% canlı ağırlık $=120 / \mathrm{NDF} \quad \%$ gibi yöntemlerle belirlenmiştir. Araştırmanın son iki yılında elde edilen çeşit verim deneme sonuçları, JUMP istatistik programında, tesadüf bloklar deneme deseninde değerlendirilmiş, \%5 önem seviyesine göre önemli çıkan ortalamalar gruplandırılmıştır.

\section{BULGULAR ve TARTIŞMA}

İki yıllık ortalamalara göre elde edilen çiçeklenme gün sayısı, bitki boyu, yaş ve kuru ot verimi, yaprak ve sap oranları, Çizelge 1'de verilmektedir. Çiçeklenme gün sayıs1, kuru ot verimi ve sap oranı bakımından genotipler arasında istatistiki olarak önemli farklılıklar saptanmıştır.

\section{Çiçeklenme Gün Sayısı (Gün)}

Çiçeklenme gün sayıları, 120.0-132.8 gün arasında değişim göstermiştir. En erken çiçeklenme 3 nolu genotipten en geç çiçeklenme ise standart çeşit olarak araştırmada yer alan Alex çeşidinden elde edildiği saptanmıştır.

\section{Bitki Boyu (cm)}

Bitki boyu ortalamaları, 102.4-117.3 cm arasında değişim göstermiştir. İskenderiye üçgülünün bitki boyunun Adana koşullarında $99.9 \mathrm{~cm}$ (Anlarsal ve ark., 1996), İzmir (Bornova) koşullarında 2 yıllık ortalamalara göre, çeşitlere göre değişmekle birlikte bitki boyunun 64-89 cm arasında değiştiği bildirilmektedir (Çelen, 1998; Soya ve ark., 2002).

\section{Yaş Ot Verimi (kg/da)}

Yaş ot verimi ortalamaları 3773-5087 kg/da arasında değişim göstermiştir. Nitekim, benzer ekolojilerde yapılan çalışmalarda, bazı İskenderiye üçgülü çeşitlerinin yeşil ot verimlerinin Çukurova koşullarında 4378 ve $4631 \mathrm{~kg} \mathrm{da}^{-1}$ (Tans1 ve ark., 1989, Anlarsal ve 
ark., 1996), İzmir koşullarında 1283-4589 $\mathrm{kg} \mathrm{da}^{-1}$ arasında (Çelen ve Soya, 1997; Soya ve ark., 2003) değiştiğini bildirmişlerdir.

\section{Kuru Madde Verimi (kg/da)}

Kuru ot verimi ortalamaları 894-1222 kg da ${ }^{-1}$ arasında değişim göstermiştir. Anlarsal ve ark.(1996), Adana koşullarında İskenderiye üçgülünün kuru ot veriminin $781.8 \mathrm{~kg} \mathrm{da}^{-1}$ olduğunu, Soya ve ark. (2003),
İzmir koşullarında farklı çeşitlerle yürütmüş oldukları iki yıllık çalışmada, çeşitlere göre değişmekle birlikte kuru ot veriminin $344-858 \mathrm{~kg} \mathrm{da}^{-1}$ arasında değiştiğini bildirmiştir. Ranjbar (2007), Sari (İran) koşullarında yılda 4 biçim aldıklarını ve 4 biçim toplamının araştırmanın birinci yılında $415 \mathrm{~kg} / \mathrm{da}$, ikinci yılında 465 $\mathrm{kg} / \mathrm{da}$ kuru ot alındığını bildirmiştir.

Çizelge 1. İskenderiye üçgülünün verime ve verimle ilişki bazı özellikleri

\begin{tabular}{|c|c|c|c|c|c|c|}
\hline Genotipler & $\begin{array}{l}\text { Çiçeklenme } \\
\text { Gün Say. (gün) }\end{array}$ & $\begin{array}{l}\text { Bitki Boyu } \\
(\mathrm{cm})\end{array}$ & $\begin{array}{l}\text { Yaş Ot Ver } \\
(\mathrm{kg} \mathrm{da})\end{array}$ & $\begin{array}{l}\text { Kuru Ot Ver. } \\
(\mathrm{kg} \mathrm{da})\end{array}$ & $\begin{array}{l}\text { Sap Oran1 } \\
(\%)\end{array}$ & $\begin{array}{l}\text { Yaprak } \\
\text { Oranı }(\%\end{array}$ \\
\hline 1 & $126.2 \mathrm{bc}^{*}$ & 108.6 & 4192 & 1057 a-e & $63.77 \mathrm{bcd}$ & 36.24 \\
\hline 2 & $123.8 \mathrm{efg}$ & 103.6 & 3920 & 939 cde & $60.07 \mathrm{abc}$ & 39.92 \\
\hline 3 & $120.0 \mathrm{k}$ & 106.3 & 4224 & $1222 \mathrm{a}$ & $63.94 \mathrm{ab}$ & 36.07 \\
\hline 4 & $122.2 \mathrm{ij}$ & 108.5 & 4399 & $1186 \mathrm{ab}$ & $65.67 \mathrm{~cd}$ & 34.33 \\
\hline 5 & $123.7 \mathrm{fgh}$ & 112.7 & 4559 & 998 a-e & $58.30 \mathrm{a}-\mathrm{d}$ & 41.70 \\
\hline 6 & $127.0 \mathrm{~b}$ & 111.3 & 4658 & 973 b-e & 60.99 a-d & 39.02 \\
\hline 7 & $122.2 \mathrm{ij}$ & 117.3 & 5084 & 1072 a-e & $63.44 \mathrm{abc}$ & 36.57 \\
\hline 8 & $124.7 \mathrm{def}$ & 115.9 & 4777 & 982 b-e & $64.30 \mathrm{~cd}$ & 35.70 \\
\hline 9 & $122.5 \mathrm{~h} 1$ & 117.1 & 4719 & 1067 a-e & $59.22 \mathrm{a}-\mathrm{d}$ & 40.79 \\
\hline 10 & $124.7 \mathrm{def}$ & 111.9 & 4963 & 1152 a-d & $60.29 \mathrm{bcd}$ & 39.70 \\
\hline 11 & $123.8 \mathrm{efg}$ & 108.0 & 3773 & 894 e & $60.18 \mathrm{bcd}$ & 39.82 \\
\hline 12 & $123.8 \mathrm{efg}$ & 109.1 & 4223 & 1020 a-e & $59.72 \mathrm{ad}$ & 40.29 \\
\hline 13 & $123.7 \mathrm{fgh}$ & 111.8 & 5087 & $1163 \mathrm{abc}$ & $62.18 \mathrm{ad}$ & 37.82 \\
\hline 14 & $124.7 \mathrm{def}$ & 116.5 & 4593 & 1109 a-e & $60.40 \mathrm{a}-\mathrm{d}$ & 39.60 \\
\hline 15 & $125.5 \mathrm{~cd}$ & 110.4 & 4517 & 1039 a-e & $58.75 \mathrm{~cd}$ & 41.25 \\
\hline 16 & $121.2 \mathrm{jk}$ & 108.9 & 4050 & 986 b-e & $61.02 \mathrm{a}-\mathrm{d}$ & 38.99 \\
\hline 17 & $125.0 \mathrm{cde}$ & 107.0 & 4252 & 1123 a-e & $59.50 \mathrm{bcd}$ & 40.51 \\
\hline 18 & $124.7 \mathrm{def}$ & 105.3 & 4194 & 1051 a-e & $64.00 \mathrm{abc}$ & 36.00 \\
\hline 19 & $125.2 \mathrm{~cd}$ & 102.4 & 4057 & 984 b-e & $66.58 \mathrm{a}$ & 33.44 \\
\hline 20 & $125.3 \mathrm{~cd}$ & 105.1 & 3807 & 926 d-e & $61.62 \mathrm{a}-\mathrm{d}$ & 38.39 \\
\hline 21 & $126.0 \mathrm{bc}$ & 102.9 & 3887 & 1034 a-e & $65.67 \mathrm{ab}$ & 34.34 \\
\hline 22 & $122.2 \mathrm{ij}$ & 111.5 & 3998 & 1035 a-e & $63.72 \mathrm{a}-\mathrm{d}$ & 32.25 \\
\hline Alex & $132.8 \mathrm{a}$ & 110.5 & 4130 & 970 b-e & $62.17 \mathrm{a}-\mathrm{d}$ & 37.84 \\
\hline Derya & $121.7 \mathrm{ij}$ & 109.3 & 4313 & 998 a-e & $57.13 \mathrm{~d}$ & 42.87 \\
\hline Popülasyon & 122.7 gh1 & 111.3 & 4295 & 1067 a-e & $62.49 \mathrm{ad}$ & 37.52 \\
\hline $\mathrm{DK}(\%)$ & 0.847 & 9.16 & 25.31 & 20.29 & 9.40 & 15.09 \\
\hline AÖF (0.05) & 1.205 & Ö.D & Ö.D. & 233.5 & 6.40 & Ö.D \\
\hline
\end{tabular}

*) Aynı sütun içerisinde benzer harf ile gösterilen ortalamalar arasında Tukey testine göre $\mathrm{P} \leq 0.05$ seviyesinde istatistiksel olarak önemli farklılık yoktur.

Sap ve Yaprak Oranı (\%)

Sap oranlar1 \% 57.13-66.58 arasında, yaprak oranları ise \% 33.44-42.87 arasında değişim göstermiştir. İskenderiye üçgülünde yaprak sap oranın önemli olduğu, yüksek yaprak/sap oranına sahip çeşitlerin daha kaliteli olduğu ve üreticiler tarafından daha çok tercih edildiği (Iannucci ve ark., 1996), toplam yaş ve kuru ottaki sap oranın yaklaşık \% 60, yaprak oranının ise $\%$ 40 olduğu (Ranjbar, 2008) bildirilmektedir.

İki yıllık ortalamalara göre elde edilen NDF, ADF, HP oranı, SKM verimi, KMT ve NYD Çizelge 2'de verilmektedir.

Nötr Deterjanda Çözünmeyen Lif, NDF (\%) ve Asit Deterjanda Çözünmeyen Lif, ADF

ADF bakımından genotipler arasında istatistiki olarak önemli farklılıklar saptanmıştır. Araştırmanın yürütüldüğü yıllarda NDF değeri \% 47.34-53.31; ADF değeri ise \% 36.15-41.01 arasında değişmiştir. El Naby ve ark. (2016) İskenderiye üçgülü çeşitlerinin ADF oranın \% 23.09 to 26.12 ; NDF değerinin ise \%32.039.12 arasında değiştiğini bildirmektedir.

\section{Ham Protein Oranı (\%)}

Ham protein oranları \%14.02-17.21 arasında değişim göstermiştir. En yüksek değer araştırmada standart çeşit olarak yer alan Derya çeşidinde saptanmıştır. İskenderiye üçgülünün HP konsantrasyonun 180-300 $\mathrm{g} \mathrm{kg}^{-1} \mathrm{KM}$ arasında değiştiği bildirilmektedir (Duke ve ark., 1981; Guessous., 1981).

\section{Sindirilebilir Kuru Madde Verimi (kg/da)}

Sindirilebilir KM verimleri 449.7-611.5 $\mathrm{kg} \mathrm{da}{ }^{-1}$ arasında değişmektedir. Bilindiği gibi ruminantlarda yemin alımı ve sindirilmesi hücre duvarındaki maddelerin komposizyonu ile ilişkilidir. Yemin sindirilimi, bitki kısımlarına, hasat dönemlerine türlere 
ve hücre duvarındaki maddenin yoğunluğu ve tipine göre de değiştiği bir çok araştırıcı tarafından da bildirilmektedir (Chesson ve ark., 1968; Buxton ve Hornstein, 1986; De Santis ve ark., 2007). Yem için hücre duvarı bileşenleri olarak bilinen NDF değerlerinin sindirebilirlikle ilişkili olduğu da bildirilmektedir (Goering and Van Soest, 1970).

Çizelge 2. İskenderiye üçgülünün ot kalitesi ile ilişki bazı özellikleri

\begin{tabular}{|c|c|c|c|c|c|c|}
\hline & $\begin{array}{l}\text { NDF (\%) } \\
(\%)\end{array}$ & $\begin{array}{l}\text { ADF } \\
(\%)\end{array}$ & $\begin{array}{c}\text { HP Oranı } \\
(\%)\end{array}$ & $\begin{array}{l}\text { SKM Verimi } \\
\text { (kg da) }\end{array}$ & $\begin{array}{l}\text { KMT } \\
(\%)\end{array}$ & NYD \\
\hline 1 & 52.59 & $40.69 \mathrm{abc}^{*}$ & 15.74 & 527.8 & 2.29 & 86.4 \\
\hline 2 & 53.31 & $40.99 \mathrm{abc}$ & 16.13 & 464.8 & 2.27 & 83.4 \\
\hline 3 & 52.74 & $40.45 \mathrm{abc}$ & 15.79 & 611.5 & 2.29 & 85.2 \\
\hline 4 & 52.23 & $40.93 \mathrm{ab}$ & 14.98 & 587.0 & 2.32 & 84.9 \\
\hline 5 & 52.04 & $39.22 \mathrm{abc}$ & 16.58 & 505.5 & 2.30 & 86.6 \\
\hline 6 & 52.38 & $40.40 \mathrm{abc}$ & 15.93 & 487.7 & 2.30 & 85.5 \\
\hline 7 & 52.20 & $40.26 \mathrm{abc}$ & 15.87 & 537.6 & 2.32 & 87.0 \\
\hline 8 & 52.18 & $40.14 a b c$ & 15.55 & 493.8 & 2.52 & 85.5 \\
\hline 9 & 51.08 & $37.19 \mathrm{~cd}$ & 16.27 & 559.9 & 2.37 & 91.2 \\
\hline 10 & 49.48 & $37.36 \mathrm{bcd}$ & 16.44 & 598.3 & 2.44 & 93.7 \\
\hline 11 & 50.71 & $38.62 \mathrm{a}-\mathrm{d}$ & 16.40 & 455.5 & 2.37 & 89.7 \\
\hline 12 & 49.45 & $37.52 \mathrm{a}-\mathrm{d}$ & 17.08 & 529.6 & 2.44 & 93.5 \\
\hline 13 & 51.55 & $39.91 \mathrm{abc}$ & 16.22 & 586.1 & 2.50 & 87.1 \\
\hline 14 & 51.55 & $39.29 \mathrm{a}-\mathrm{d}$ & 16.31 & 560.4 & 2.34 & 88.7 \\
\hline 15 & 50.66 & $37.76 \mathrm{a}-\mathrm{d}$ & 16.39 & 538.7 & 2.37 & 91.5 \\
\hline 16 & 47.34 & $36.15 \mathrm{~d}$ & 15.11 & 483.2 & 2.55 & 102.2 \\
\hline 17 & 49.84 & $37.61 \mathrm{a}-\mathrm{d}$ & 15.86 & 581.9 & 2.40 & 93.4 \\
\hline 18 & 50.82 & $38.48 \mathrm{a}-\mathrm{d}$ & 15.99 & 533.5 & 2.37 & 89.2 \\
\hline 19 & 50.74 & $39.38 \mathrm{a}-\mathrm{d}$ & 14.02 & 475.1 & 2.38 & 91.8 \\
\hline 20 & 50.94 & $38.84 \mathrm{a}-\mathrm{d}$ & 14.87 & 449.7 & 2.35 & 90.4 \\
\hline 21 & 51.84 & $40.47 \mathrm{abc}$ & 15.84 & 508.1 & 2.32 & 85.3 \\
\hline 22 & 52.56 & $40.34 \mathrm{abc}$ & 15.83 & 517.2 & 2.29 & 80.5 \\
\hline Alex & 50.78 & $41.01 \mathrm{a}$ & 16.08 & 496.9 & 2.35 & 89.9 \\
\hline Derya & 50.19 & $37.68 \mathrm{a}-\mathrm{d}$ & 17.21 & 517.0 & 2.40 & 93.6 \\
\hline Popülasyon & 51.84 & $39.87 \mathrm{abc}$ & 16.05 & 541.3 & 2.30 & 86.9 \\
\hline DK $(\%)$ & 6.18 & 8.15 & 10.98 & 20.43 & 6.51 & 10.65 \\
\hline AÖF $(0.05)$ & Ö.D. & 3.69 & Ö.D. & Ö.D. & Ö.D. & Ö.D. \\
\hline
\end{tabular}

*) Aynı sütun içerisinde benzer harf ile gösterilen ortalamalar arasında Tukey testine göre $\mathrm{P} \leq 0.05$ seviyesinde istatistiksel olarak önemli farklılık yoktur. Nötr Deterjan Lif (NDF), Asit Deterjan Lif (ADF), Ham Protein (HP), Sindirilebilir Kuru Madde (SKM), Kuru Madde Tüketimi (KMT), Nispi Yem değeri (NYD)

\section{Kuru Madde Tüketimi (\%)}

Kuru madde tüketimi \% 2.27-2.55 arasında değişmekte olup, en yüksek değer 16 nolu genotipde saptanmıştır. El Naby ve ark. (2016) KMT \%3.07-3.75 arasında değiştiğini bildirmektedir.

\section{Nispi Yem Değeri (NYD)}

Nispi yem değeri 80.5-102.2 arasında değişmekte olup, en yüksek değer 16 nolu genotipte saptanmıştır. El Naby (2016), İskenderiye üçgülünde yapmış olduğu çalışmada NYD 149.9-197.3 arasında değiştiğini bildirmiştir.

\section{SONUÇ}

İki yıllık çeşit verim denemeleri sonucu $3,4,13,10,17,14$ ve 7 no'lu genotiplerin verim ve bazı kalite değerleri bakımından diğer genotiplerden üstün oldukları saptanmıştır. Söz konusu genotipler, ileride yapılacak ıslah çalışmalarında değerlendirilecektir.

\section{TEŞEKKÜR}

*) $\mathrm{Bu}$ çalışma, TAGEM tarafindan desteklenmiş olan TAGEM/TA/11/01/003 nolu projenin bir bölümüdür. Kendilerine projeye desteklerinden dolayı teşekkür ederiz.

\section{KAYNAKLAR}

Açıkgöz E 2001. Yem Bitkileri, Uludağ Üniversitesi Güçlendirme Vakfı Yayın No:182, Vipaş Aş Yayın No:58, $584 \mathrm{~s}$.

Anlarsal AE, Ülger AC, Gök M, Yücel C, Çakir B, Onaç I 1996. Çukurova'da tek yillık baklagil yem bitkisi + misır üretim sisteminde baklagillerin ot verimleri ile azot fiksasyonlarının Saptanması ve misır üretiminde azot kullanımını azaltma olanakları. Türkiye 3. Çayır- Mera ve Yem Bitkileri Kongresi. 17-19 Haziran, Erzurum. 362-368. 
Anonymous 1987. Introduction to breeding of forage crops. International Center for Agricultural Research in the Dry Areas (ICARDA), ICARDA Training Course 1979, Reprinted, $1987.103 \mathrm{p}$.

Buxton DR, Hornstein JS 1986. Cell wall concentration and components stratified canopies of alfalfa, birdsfoot trefoil and red clover. Crop Sci., 26:180-184.

Chesson A, Stewart CS, King YP 1986. Degradation of isolated grass mesophyll, epidermis and fiber cell walls in the rumen and by rumen bacteria. J. Appl.Bacteriol., 60:327-336.

Çelen AE 1998., Bazı İskenderiye Üçgülü (Trifolium alexandrinum L.) Çeşitlerinin tohum verimi ve verim özellikleri üzerinde araştırmalar. Anadolu, J. of AARI 8 (2), 1-7.

Çelen AE, Soya H 1997. Ege bölgesi koşullarında bazı İskenderiye üçgülü (Trifolium alexandrinum L.) çeşitlerinin adaptasyonu ve verim denemeleri, Türkiye II. Tarla Bitkileri Kongresi, 22-25 Eylül 1997, Samsun, 411-415.

Çelen AE, Soya H, Akbari N 1991. Kışlık ara ürün olarak kimi üçgül+buğdaygil yem bitkilerinden yararlanma. Türkiye 2. ÇM ve Yembitkileri Kong., 28-31 Mayıs 1991, Gümüldür-İzmir,S:254-262.

De Santis G, Iannucci A, Chiaravalle E 2007. Changes During Growth in Cell Wall Components of Berseem Clover Under Different Cutting Treatments in a Mediterranean Region. Italian Journal of Agronomy 02/2011;

2(3). DOI: 10.4081/ija.2007.321. Source: DOAJ

Duke JA 1981. Trifolium alexandrinum L. In: Duke JA, Ed. Handbook of legumes of world economic importance. New York: Plenum Press; pp. 234-237.

El-Naby A, Zeinab M, Rajab M N, Walaa M. E, Abd El-Aziz T. K. 2016. Evaluation of Quality Characters of Some Egyptian clover Genotypes. International Journal of Applied and Pure Science and Agriculture (IJAPSA) Volume 02, Issue 04, [April - 2016] e-ISSN: 2394-5532, p-ISSN: 2394823X.

Gençkan MS 1983. Yem Bitkileri Tarımı. Ege Üniversitesi Ziraat Fakültesi, İzmir, 519 s.
Goering HK, Van Soest PJ 1970. Forage fiber analyses (apparatus reagents, procedures and some applications). USDA ARS, Agric. Handb. 379. US Government Printing Office, Washington D.C.

Guessous F 1981. Age, date of cutting and temperature as factors affecting chemical composition of berseem (Trifolium alexandrinum L.). Proc. XIV Int. Grassld. Congress, Lexington: Kentucky; pp. 475-8.

Iannucci A, Di Fonzo N, Martiniello P 1996. Effects of harvest manegement on the growth dynamics forage and seed yield in berseem clover, European $\mathrm{J}$. Argon., 14:303-314.

Jaranyama P, Garcia AD 2004. Understanding relative feed value (RFV) and relative forage quality (RFQ). College of Agriculture and Biological Sciences, South Dakota State University, USDA.

Ranjbar GA 2007. Forage and hay yield performance of different berseem clover (Trifolium alexandrinum L.) genotypes in Mazandaran Conditions. Asian J. of Plant Sciences, 6 (6):1006-1011.

Ranjbar GA 2008. Using leaf production efficiency as an effective criterion for evaluation of berseem clover (Trifolium alexandrinum L.) cultivars. Journal of Agriculture \& Social Science, 4:107-111.

Shenk JS, . Westerhaus MO 1994. The application of Near infrared reflectance spectroscopy (NIRS) to forage analysis, 406-409, (1994). In: G.C. Fahey et al. (ed.) Forage quality, evaluation, and utilization. ASA, CSSA, and SSSA, Madison, WI.

Soya H, Geren H, Kır B 2002. Bazı İskenderiye üçgülü çeşitlerinin tohum verimi ve verim özelliklerinin saptanması üzerine bir araştırma. Türkiye I. Tohumluk Kongresi, 11-13 Eylül- 2002, İzmir, 239242.

Soya H, Geren H, Kır B 2003. Bazı İskenderiye üçgülü çeşitlerinin verim özelliklerinin saptanması üzerine bir araştırma. Türkiye 5.Tarla Bitkileri Kong., 13-17 Ekim 2003, Diyarbakır, 322-325.

Tansı V, Anlarsal AE, Sağlamtimur T, Gülcan H 1989. Çukurova'da üç İskenderiye üçgülü çeşidinde farklı biçim yüksekliklerinin verim ve verim unsurlarına etkisi üzerinde bir araştırma. Ç.Ü. Ziraat Fakültesi Dergisi, 4 (5):69-82. 